\title{
COMPARAÇÃO DE METODOLOGIAS PARA DETERMINAÇÃO DA ACIDEZ TITULÁ VEL DE LEITE UHT (Ultra High Temperature), PRODUZIDOS EM DIFERENTES ESTAÇÕES DO ANO
}

\author{
Elisandra Rigo ${ }^{1}$, Darlene Cavalheiro ${ }^{1}$, Gabriela Polmann², Vinicius Badia ${ }^{2}$ e Alexandra Fabíola \\ Becker $^{2}$ \\ ${ }^{1}$ Universidade do Estado de Santa Catarina, Departamento de Engenharia de Alimentos e Engenharia \\ Química - DEAQ, Doutora em Engenharia de Alimentos \\ ${ }^{2}$ Universidade do Estado de Santa Catarina, Departamento de Engenharia de Alimentos e Engenharia \\ Química - DEAQ, graduados em Engenharia de Alimentos \\ E-mail para contato: elisandra.rigo@udesc.br

\begin{abstract}
RESUMO - O leite é um meio natural para crescimento de micro-organismos, neste sentido, a análise de acidez é considerada um teste de qualidade higiênico-sanitário e prova de rotina na indústria de lácteos. Segundo as metodologias descritas na normativa $\mathrm{n}^{\circ} 68$ como método A e método $\mathrm{B}$, resultam na acidez em ${ }^{\circ}$ Dornic, com isso o objetivo visa comparar os métodos e verificar se há influência das estações do ano nos resultados de acidez para o leite UHT (Ultra High Temperature) integral, semidesnatado e desnatado, totalizando 511 litros analisados. Todos os leites avaliados apresentaram acidez titulável entre a faixa estabelecida pela legislação $\left(14\right.$ a $\left.18{ }^{\circ} \mathrm{D}\right)$. Os resultados desta pesquisa indicaram haver diferença entre os valores de acidez mensurados pelos métodos A e B, sendo os menores valores de acidez obtidos pelo método B para o leite integral no outono, e desnatado e semidesnatado no verão.
\end{abstract}

Palavras-chave: Qualidade. Legislação. Graus Dornic.

DOI: $10.5965 / 24473650412018125$

\section{INTRODUÇÃO}

O leite consiste em uma fonte significativa de energia, proteína, gordura e cálcio na dieta alimentar (MUEHLHOFF; BENNETT; MCMAHON, 2013), é considerado uma solução coloidal, onde partículas em suspensão estão dispersas em um solvente (GONÇALVES, 2012), substâncias como gorduras no estado emulsificado, proteínas em estado coloidal, compostos orgânicos e inorgânicos solubilizados como sais, lactose, vitaminas hidrossolúveis e substâncias nitrogenadas não proteicas (GAUCHEROM, 2005), constitui o ponto de partida para qualquer produto lácteo de boa qualidade (CATTANEO; HOLROYD, 2013). 
Recebido em:

$05 / 09 / 2018$

Aceito em:

$10 / 12 / 2018$

As variações quanto à composição do leite dependem de fatores como espécie animal, raça, individualidade animal, intervalo entre ordenhas, variação durante a ordenha, período de lactação, estação do ano, alimentação, temperatura, doenças, idade do animal e condições climáticas (GONZÁLES et al., 2001).

O leite in natura caracteriza-se como um produto rico em nutrientes e com um pH próximo a neutralidade e alta atividade de água, constituindo um meio de cultura natural para o crescimento de micro-organismos de diversas naturezas, necessitando atenção especial quanto aos cuidados higiênicos e de manejo, buscando garantir sua qualidade e segurança dos alimentos (REFSHOLT et al., 2007; PINTO et al., 2013).

Altas contagens bacterianas prejudicam a aceitabilidade, o valor nutricional, o rendimento e a vida útil do leite e produtos lácteos, sem contar em implicações adicionais à saúde pública se bactérias patogênicas contaminarem o leite (OLIVEIRA et al. 2011; COSTA SOBRINHO et al., 2012; GIACOMETTI et al., 2012; HILL et al., 2012).

Visando monitorar a qualidade da obtenção do leite tem-se um conjunto de normativas e atividades relativas que prevê as boas práticas agropecuárias aplicadas a pecuária do leite (BRASIL, 2011), além das que oficializam os métodos analíticos físico-químicos para controle de leite e produtos lácteos (BRASIL, 2006), bem como o Regulamento Técnico de Identidade e Qualidade de Produtos Lácteos do Ministério da Agricultura, Pecuária e Abastecimento.

Segundo o Regulamento Técnico de Identidade e Qualidade de Produtos Lácteos do Ministério da Agricultura, Pecuária e Abastecimento (BRASIL, 1997), o leite UHT deve possuir acidez entre 14 a $18{ }^{\circ}$ Dornic $(0,14$ a 0,18 g de ácido láctico/100 mL). Santos e Fonseca (2004) observaram que quando o leite é obtido sob condições inadequadas de higiene e refrigeração deficiente, ocorre o aumento de ácidos orgânicos, em especial do ácido lático, resultando na chamada acidez adquirida.

Neste sentido, a determinação da acidez do leite é muito utilizada, e considerada como teste de qualidade ou prova de rotina na indústria de laticínios, pois tem a capacidade de fornecer parâmetros sobre o estado de conservação do produto e é regulamentada pela Instrução Normativa $\mathrm{n}^{\circ} 68$ (BRASIL, 2006). O que é geralmente conhecido como acidez do leite é o resultado de titulação (ALAIS, 1971). A acidez titulável é a capacidade de combinação com uma base (GODED Y MUR, 1966).

Assim, a presente pesquisa buscou o monitoramento da acidez do leite UHT integral, semidesnatado e desnatado, produzidos por uma indústria láctea da região Oeste de Santa Catarina, pela análise de acidez realizada segundo a Instrução Normativa nº 68 (BRASIL, 2006) comparando-se os valores obtidos pelos métodos analíticos $\mathrm{A}$ e $\mathrm{B}$, de acordo com o realizado em análises de rotina do padrão de qualidade interno das indústrias lácteas, estabelecidos segundo o Regulamento Técnico de Identidade e Qualidade (RTIQ) 370 (BRASIL, 1997), bem como analisar a influência das estações do ano sobre a acidez do leite. Ressalta-se que segundo a Instrução Normativa $n^{\circ} 68$ (BRASIL, 2006) as metodologias devem resultar em mesmo valor de acidez titulável. Considerando que a Instrução Normativa em vigo no momento é a no 30, de 26 de junho de 2018 (BRASIL, 2018). 


\section{MATERIAS E MÉTODOS}

Os experimentos foram realizados no Laboratório da Qualidade dos Alimentos do Departamento de Engenharia de Alimentos e Engenharia Química - DEAQ, da Universidade do Estado de Santa Catarina - UDESC, Pinhalzinho, Santa Catarina.

As amostras de leite UHT integral, desnatado e semidesnatado, foram recebidas diretamente da empresa produtora de lácteos com registro de SIF, e a amostragem baseada na produção dos respectivos leites no período de abril de 2013 até abril de 2014.

O leite integral com produção anual de 129.230.292 litros/ano, semidesnatado com 8.563.520 litros/ano e desnatado 9.545.226 litros/ano, assim, resultando na amostragem de 14 litros por semana para integral e 7 litros por semana para semidesnatado e desnatado durante as diferentes estações do ano, conforme apresentado na Tabela 1. Para o leite integral foram realizadas 21 amostragens de 14 litros, semidesnatado 15 amostragens de 7 litros e desnatado 16 amostragens de 7 litros, totalizando em 511 litros de leite analisados. Basicamente a amostragem foi realizada pela relação do cálculo da retirada de duas vezes a raiz quadrada da produção total de cada leite estudado.

Tabela 1 - Número de amostras de cada tipo de leite UHT avaliado no período de junho de 2014 até fevereiro de 2016 em cada estação do ano

\begin{tabular}{cccc}
\hline & \multicolumn{3}{c}{ Quantidade de amostras analisadas (Litros) } \\
\cline { 2 - 4 } Estações & Integral & Semidesnatado & Desnatado \\
\hline Outono & 56 & 21 & 21 \\
\hline Inverno & 126 & 42 & 35 \\
\hline Primavera & 56 & 21 & 28 \\
\hline Verão & 56 & 28 & 28 \\
\hline Total & $\mathbf{2 9 4}$ & $\mathbf{1 0 5}$ & $\mathbf{1 1 2}$ \\
\hline
\end{tabular}

Fonte: elaborado pelo autor (2018)

\subsection{Determinação da Acidez Titulável}

A avaliação da acidez titulável das amostras foi realizada pela metodologia para determinação de acidez titulável de leite fluído descritas no anexo V - Métodos Quantitativos, como métodos A e B, definida na Instrução Normativa $n^{\circ} 68$ do MAPA (BRASIL, 2006), buscando comparar os valores expressos em graus Dornic de cada metodologia.

$\mathrm{O}$ método A consiste em transferir $10 \mathrm{~mL}$ da amostra para um erlenmeyer de $125 \mathrm{~mL}$ e diluir com $40 \mathrm{~mL}$ de água. Posteriormente adicionar $2 \mathrm{~mL}$ de solução alcoólica de fenolftaleína a $1 \%$ e titular com solução alcalina de hidróxido de sódio $0,1 \mathrm{~N}$ até a primeira coloração rosa forte persistente por aproximadamente 30 segundos. Onde se aplicação a Equação 1 para obtenção da acidez titulável 
em porcentagem ${ }^{\circ}$ Dornic:

$$
\text { Acidez }\left({ }^{\circ} \text { Dornic) }=\frac{\mathbf{V} \times \mathbf{f} \times 1000}{\mathbf{v}} \quad \text { Equação } 1\right.
$$

Onde:

$\mathrm{V}=$ volume de solução de hidróxido de sódio $0,1 \mathrm{~N}$ gasto na titulação, em mL;

$\mathrm{v}=$ volume da amostra, em $\mathrm{mL}$;

$\mathrm{f}$ = fator de correção da solução de hidróxido de sódio $0,1 \mathrm{~N}$;

0,09 = fator de conversão do ácido lático;

$\mathrm{N}=$ normalidade de solução de hidróxido de sódio $0,1 \mathrm{~N}$.

Para o método B, $10 \mathrm{~mL}$ da amostra para o béquer e adicionar 4 - 5 gotas da solução de fenolftaleína a $1 \%$ e titulação com solução alcalina de hidróxido de sódio $0,1 \mathrm{~N}$ até aparecimento de coloração rósea persistente por aproximadamente 30 segundos. Seguindo a Equação 2 para obtenção da acidez em ${ }^{\circ}$ Dornic.

Onde:

$$
\text { Acidez ( }{ }^{\circ} \text { Dornic) }=\mathbf{V x} \mathbf{f} \mathbf{x} \mathbf{0}, 9 \times 10 \quad \text { Equação } 2
$$

$\mathrm{V}=$ volume da solução de hidróxido de sódio $0,1 \mathrm{~N}$ gasto na titulação, em mL;

$\mathrm{f}=$ fator de correção da solução de hidróxido de sódio $0,1 \mathrm{~N}$;

0,9 = fator de conversão do ácido lático;

$10=$ transformação de ácido lático para grau Dornic.

Considerando os cálculos pelos dois métodos a principal diferença é que o método A considera o volume da amostra a ser titulado.

\subsection{Análise Estatística}

Os dados experimentais foram expressos como média \pm desvio padrão. Para a análise estatística foi utilizado o software Statistica ® 10.0 sendo realizado o teste de Tukey, com nível de 95\% de confiança.

\section{RESULTADOS E DISCUSSÕES}

\subsection{Avaliação da Diferença Significativa Entre os Métodos}

O clima é dividido nas estações do ano: primavera, verão, outono e inverno e distinguem-se pelas condições meteorológicas e estas tem influência direta na produção animal (MEDEIROS; VIEIRA, 2009), considerando a temperatura do ar, radiação solar e umidade, seja no crescimento de 
Recebido em:

$05 / 09 / 2018$

Aceito em:

$10 / 12 / 2018$

vegetação e taxas de crescimento, bem como, no favorecimento de diversas doenças e disfunções em vacas produtoras de leite, como a mastite (RIEKERINK; BARKEMA; STRYHN, 2007).

Nesse contexto, a Tabela 2 apresenta a avaliação da acidez titulável em graus Dornic $\left({ }^{\circ} \mathrm{D}\right)$ do leite integral, desnatado e semidesntado (UHT) obtida das produções nas diferentes estações do ano. Para o leite integral o Método A não houve diferença significativa $(p<0,05)$ entre as estações, já para o método B, observou-se que apenas a estação da primavera diferiu significativamente das demais. $\mathrm{Na}$ comparação entre os métodos $A$ e $B$ na primavera houve diferença significativa $(p<0,05)$. A maior acidez $\left(15,40 \pm 0,36^{\circ} \mathrm{D}\right)$ foi observada na estação de inverno no método $\mathrm{A}$ e a menor no outono $\left(14,13 \pm 0,63^{\circ} \mathrm{D}\right)$ pelo método $\mathrm{B}$, indicando que a conservação e o controle de qualidade da matéria prima possivelmente permitiram que as estações do ano relatadas como as que causam aumento da acidez, devido a elevação da temperatura do ambiente, não foram as que resultaram nos valores mais elevados deste parâmetro de qualidade (BRITO et al., 2007; MOREIRA, 2014).

Tabela 2 - Avaliação da acidez titulável em Graus Dornic $\left({ }^{\circ} \mathrm{D}\right)$ do leite integral, leite desnatado e semidesnatado (UHT) nas diferentes estações do ano segundo as metodologias descritas na IN 68 (MAPA, 2006)

Leite Integral Leite Desnatado Leite Semidesnatado

\begin{tabular}{lrrrrrr}
\hline Estações do Ano & Método A & Método B & Método A & Método B & Método A & Método B \\
Outono & $14,99 \pm 0,56^{\mathrm{aA}}$ & $14,13 \pm 0,63^{\mathrm{bA}}$ & $15,51 \pm 0,31^{\mathrm{aA}}$ & $15,58 \pm 0,33^{\mathrm{aA}}$ & $15,46 \pm 0,38^{\mathrm{aA}}$ & $15,15 \pm 0,07^{\mathrm{bA}}$ \\
Inverno & $15,40 \pm 0,36^{\mathrm{aA}}$ & $14,76 \pm 0,41^{\mathrm{bA}}$ & $15,38 \pm 1,29^{\mathrm{aA}}$ & $14,98 \pm 0,77^{\mathrm{aB}}$ & $15,80 \pm 0,53^{\mathrm{aA}}$ & $14,99 \pm 0,41^{\mathrm{bA}}$ \\
Primavera & $15,32 \pm 1,38^{\mathrm{aA}}$ & $14,94 \pm 0,23^{\mathrm{aB}}$ & $15,03 \pm 0,73^{\mathrm{aA}}$ & $15,65 \pm 0,57^{\mathrm{bA}}$ & $15,53 \pm 0,33^{\mathrm{aA}}$ & $15,31 \pm 0,27^{\mathrm{bB}}$ \\
Verão & $15,03 \pm 0,21^{\mathrm{aA}}$ & $14,40 \pm 0,38^{\mathrm{bA}}$ & $15,18 \pm 0,46^{\mathrm{aA}}$ & $14,80 \pm 0,60^{\mathrm{cB}}$ & $14,99 \pm 0,29^{\mathrm{aA}}$ & $14,96 \pm 0,44^{\mathrm{aB}}$
\end{tabular}

Médias \pm desvio padrão seguidas de letras minúsculas iguais em cada coluna não diferem significativamente $(\mathrm{p}<0,05)$ em relação à acidez do leite em diferentes estações em cada método. Médias \pm desvio padrão seguidas de letras maiúsculas iguais em cada linha não diferem significativamente $(\mathrm{p}<0,05)$ em relação à acidez do leite entre os métodos na mesma estação do ano (Teste de Tukey).

Fonte: elaborado pelo autor (2018)

A avaliação da acidez titulável em graus Dornic para o leite desnatado (UHT) também apresentado na Tabela 2. Apenas o método B apresentou diferença significativa entre as estações do ano, sendo os valores de acidez do outono e inverno diferentes da primavera e também do verão $(\mathrm{p}<0,05)$. A diferença dos valores de acidez entre os métodos na mesma estação do ano foi observada nas estações de inverno e verão considerando $(\mathrm{p}<0,05)$. Para o leite desnatado a maior acidez foi na primavera $\left(15,65 \pm 0,57^{\circ} \mathrm{D}\right)$ e a menor foi no verão $\left(14,80 \pm 0,60^{\circ} \mathrm{D}\right)$, ambas quantificadas pelo método B. Considerando que a acidez é um parâmetro de controle no qual reflete diretamente a qualidade dos leites processados na indústria (MAGRI, 2015), os resultados demonstram que a 
Recebido em:

$05 / 09 / 2018$

Aceito em:

$10 / 12 / 2018$

indústria fornecedora das amostras apresenta um eficiente controle das etapas do processamento. Sendo que o resfriamento adequado do leite cru, após ser ordenhado, retardar o crescimento de microorganismos e consequentemente, a acidificação da matéria prima (FOSCHIERA, 2004).

Para a acidez em graus Dornic do leite semidesnatado (UHT) apresentado na Tabela 2, o método A destaca-se que não houve diferença significativa entre as estações do ano $(\mathrm{p}<0,05)$, já para o método B observou-se que as estações outono, inverno e primavera diferiram significativamente em relação ao verão. Analisando-se os resultados entre os métodos A e B observou-se diferença significativa $(\mathrm{p}<0,05)$ na primavera e verão. O leite semidesnatado que resultou em maior valor de acidez $\left(15,80 \pm 0,53^{\circ} \mathrm{D}\right)$ foi produzido no inverno quantificado pelo método $\mathrm{A}$ e a menor quando avaliado pelo método B no verão $\left(14,96 \pm 0,44^{\circ} \mathrm{D}\right)$.

De acordo com os dados obtidos observou-se em todos os tipos de leite avaliados (integral, desnatado e semidesnatado) na Tabela 2 , que não houve diferença $(\mathrm{p}<0,05)$ da acidez entre as estações do ano quando o método A foi utilizado. Quando a acidez foi quantificada pelo método B, para todos os tipos de leites, somente aqueles produzidos no outono e inverno não apresentaram diferença $(\mathrm{p}<0,05)$. Ressalta-se, no entanto, que todos os leites avaliados no presente estudo, integral, desnatado e semidesnatado apresentaram acidez titulável entre a faixa estabelecida pelo padrão de identidade e qualidade do leite UHT, que indica acidez de 14 a 18 graus Dornic (BRASIL, 1996).

Fabro et al. (2006) e colaboradores analisaram a acidez de 266 amostras de leite cru da Argentina comparando a metodologia da Official Methods of Analysis (AOAC, 1990) com a definida pelo Instituto Nacional de Racionalización de Materiales (IRAM, 1976), sendo estas próximas as definidas na Instrução Normativa $N^{\circ} 68$ (Brasil, 2006). Os resultados apresentaram diferença significativa $(\mathrm{p}<0,05)$ entre os métodos avaliados, indicando possivelmente o tamanho da amostra e a sua diluição como a causa da diferença, considerando que a mudança de cor ocorreria mais rapidamente, utilizando menor quantidade de solução alcalina, resultando em menor acidez no caso do método estabelecido pelo IRAM. Ressalta-se que o método B (BRASIL, 2006) segue a metodologia descrita pelo Instituto Nacional de Racionalización de Materiales (IRAM, 1976).

No presente estudo, obteve comportamento similar ao relatado por Fabro et al. (2006) e colaboradores, considerando que para todos os tipos de leite UHT avaliados (integral, desnatado e semidesnatado, Tabela 2), os menores valores de acidez foram obtidos no método $\mathrm{B}$, sendo para o leite integral no outono e para os leites desnatado e semidesnatado no verão, demonstrando que a estação do ano não teve influência sobre a acidez e sim o método (A e B) utilizado na quantificação.

Em seus estudos Goded e Mur (1966) observaram que existem variações entre os métodos de avaliação da acidez em cada País e isso pode ser atribuído a alguns fatores como a concentração da solução de $\mathrm{NaOH}$, o volume de leite a ser titulado, e a concentração de fenolftaleína. Ainda, Alias (1971) relatou que embora a medição da acidez no leite seja simples de realizar-se, existem várias fontes de erro que podem ser relacionadas como a quantidade de indicador, velocidade de titulação, diluição da amostra, temperatura do leite e a determinação do ponto final da titulação.

Os resultados deste estudo indicaram que a acidez dos leites UHT integral, semidesnatado e desnatado obtida na primavera sempre apresentou diferença em comparação a observada no inverno. Fernandes, Pereira e Pinho (2013) analisaram a diferença da sazonalidade em leite cru pelo método A 
Recebido em:

$05 / 09 / 2018$

Aceito em:

$10 / 12 / 2018$

e obtiveram diferenças significativas $(p<0,05)$ em relação a acidez do leite das estações primavera e outono. Na presente pesquisa a acidez do leite UHT integral e desnatado quantificada pelo método B apresentou diferença $(\mathrm{p}<0,05)$ em relação ao outono e primavera.

Segundo o estudo de Fanti et al. (2008) a acidez Dornic variou significativamente durante as estações do ano, sendo que no verão a acidez média foi mais alta em relação aos outros períodos $\left(16,78^{\circ} \mathrm{D}\right)$. No presente estudo o leite UHT semidesnatado produzido no inverno apresentou maior acidez $\left(15,80 \pm 0,53{ }^{\circ} \mathrm{D}\right)$ em comparação ao desnatado e integral na mesma estação (Tabela 2$)$.

Segundo West (2003) em relação às estações do ano, quando se tem altas temperaturas, dias longos e sombreamento insuficiente como no verão, não se tem as melhores condições para as vacas em lactação, o que vai interferir diretamente na composição química do leite. Pesquisas relacionam o estresse térmico com o aumento da contagem de células somáticas do leite e a ocorrência de mastite (WEGNER et al.,1976; SMITH; TODHUNTERM; SCHOENBERGER, 2008). Durante a estação quente, ocorre um agravamento das principais propriedades do leite, em particular, a redução da acidez titulável (MALACARNE et al., 2005).

Kennedy et al. (1982) observaram valores mais baixos nos meses de verão e mais altos nos meses de inverno. Assim, constatou maior incidência de mastite em vacas em ambiente fechado, no inverno, do que em pastagem, no verão. O resultado foi justificado por no inverno as vacas estarem mais sujeitas a estresses do ambiente e infecções por bactérias, consequentemente, alterando o pH do leite.

Elgersma et al. (2004) e colaboradores observaram mudanças na composição do leite quando ocorria alteração na alimentação das vacas de uma dieta a base de silagem para uma baseada em pastagem. Segundo o estudo de Fredeen (1996), a nutrição é uma das causas da variação nos teores de proteína e gordura do leite onde a gordura é o componente de maior variabilidade do leite, e esta é influenciada pela genética e por fatores nutricionais e ambientais e, consequentemente, contribui diretamente para acidez do leite.

De acordo com Paula et al. (2008), as maiores porcentagens de gordura, proteína e sólidos totais, concentraram-se no outono, onde a produção de leite foi significativamente inferior às demais estações do ano. O menor teor de gordura, proteína e sólidos totais observados na primavera/inverno. Outras pesquisas também mostram variação sazonal nas concentrações dos principais componentes do leite (LINDMARK-MANSSON et al., 2003; LOCK e GARNSWORHY, 2003).

\subsection{Comparação da Acidez $\left({ }^{\circ}\right.$ Dornic) ente Método A e Método B em Leite Integral, Desnatado e Semidesnatado em cada estação do ano}

A Figura 1 apresenta os valores médios de acidez obtida por diferentes métodos para a estação outono. A Figura 1 (a) apresenta os valores médios da acidez realizada em 4 lotes de 14 amostras cada de leite integral com predominância de maiores valores de acidez para as amostragens do método A. Para a Figura 1 (b) foram analisados 3 lotes com 7 amostras cada de leite desnatado e percebeu-se que ocorreram variações entre a acidez pelos diferentes métodos. Com relação à Figura 1 (c), também 3 lotes com 7 amostras cada de leite semidesnatado foram avaliados, ocorreu variação no perfil de 
Recebido em:

$05 / 09 / 2018$

Aceito em:

$10 / 12 / 2018$

acidez entre os métodos, porém com predominância de maiores valores de acidez para o método A. Assim, totalizando em 10 lotes analisados na estação outono para os diferentes leites por diferentes metodologias de determinação de acidez.

Figura 1 - Comparação dos valores de acidez ( ${ }^{\circ}$ Dornic) do leite integral (a), leite desnatado (b) e leite semidesnatado (c) obtida pelos diferentes métodos A e B para as amostragens realizadas no outono
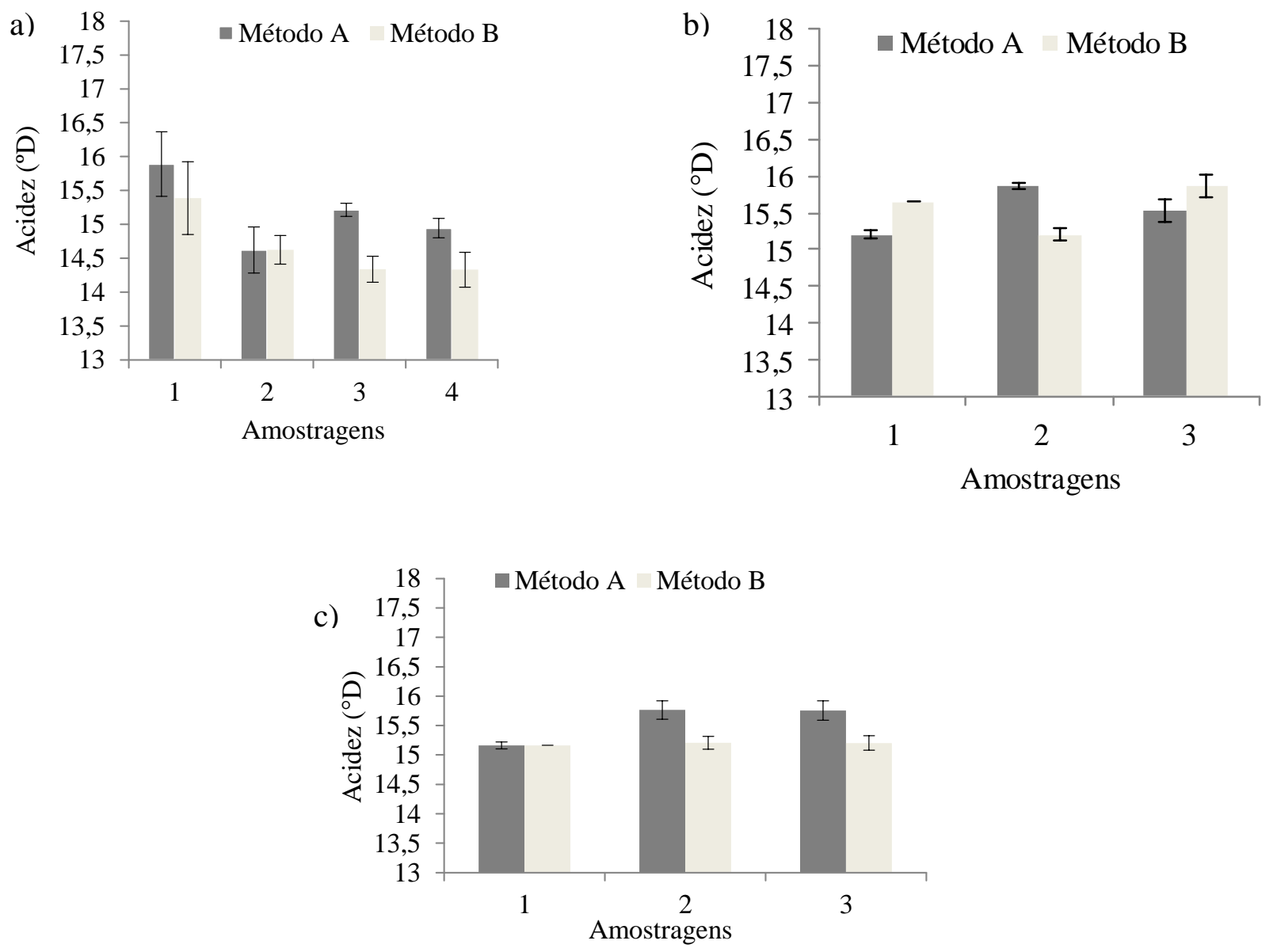

Fonte: elaborado pelo autor (2018) 
A Figura 2 apresenta os valores médios de acidez obtida por diferentes métodos para a estação inverno. Verifica-se na Figura 2 (a), para as análises das médias da acidez de 9 lotes de 14 amostras cada de leite integral, que os resultados com o método A foram maiores quando comparados com o método B. Com relação à Figura 2 (b), foram analisados 5 lotes com 7 amostras cada de leite desnatado, e verificou-se que o método A obteve valores maiores que o método B. Para Figura 2 (c), foram analisados 6 lotes com 7 amostras cada de leite semidesnatado e obteve-se para o método A maiores valores de acidez em comparação com o método B. Assim, totalizando em 20 lotes analisados na estação inverno para os diferentes leites, para os quais obteve-se valores de acidez maior quando utilizou-se o método A.

A Figura 3 apresenta os valores médios de acidez obtida por diferentes métodos para a estação primavera. Verifica-se na Figura 3 (a), para as análises das médias da acidez em 4 lotes de 14 amostras cada de leite integral, que com o método A atingiu-se maiores valores de acidez quando comparados com os valores de acidez do método B. Para Figura 3 (b) foram analisados 4 lotes com 7 amostras cada de leite desnatado, sendo que para os resultados obtidos com o método A e o método B verificou-se que ocorreram variações entre a acidez. Na Figura 3 (c) analisou-se 3 lotes com 7 amostras cada de leite semidesnatado, e obteve-se que para o método A a acidez atingiu valores maiores que para o método B. Assim, totalizando em 11 lotes analisados na estação primavera para os diferentes leites pelos diferentes métodos.

A Figura 4 apresenta os valores médios de acidez obtida por diferentes métodos para a estação verão. Verifica-se na Figura 4 (a), onde foram analisadas as médias da acidez em 4 lotes de 14 amostras cada de leite integral, que quando utilizou-se o método $\mathrm{A}$ atingiu-se maiores valores maiores de acidez quando comparados com os valores de acidez do método B. Para a Figura 4 (b) analisaram-se 4 lotes com 7 amostras cada de leite desnatado, na qual percebeu-se que para o método A foram obtidos maiores valores de acidez quando comparados com a acidez do método B. Na Figura 4 (c) analisou-se 4 lotes com 7 amostras cada de leite semidesnatado e observou-se um comportamento semelhante entre a acidez do método A e método B. 
Recebido em:

$05 / 09 / 2018$

Aceito em:

$10 / 12 / 2018$

Figura 2 - Comparação da acidez ( ${ }^{\circ}$ Dornic) do leite integral (a), leite desnatado (b) e leite semidesnatado (c) obtida pelos diferentes métodos, A e B, para as amostragens realizadas no inverno
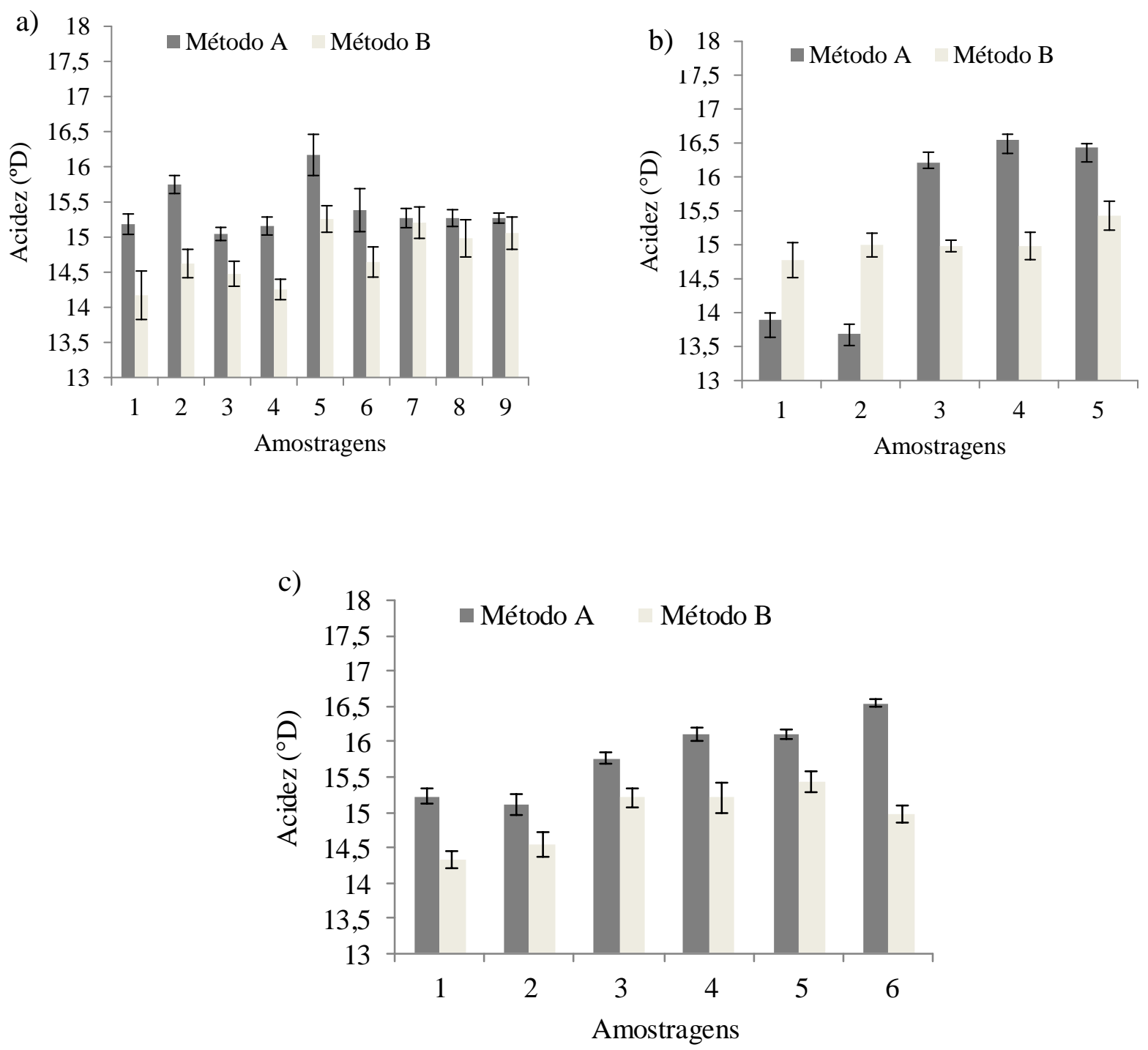

Fonte: elaborado pelo autor (2018) 
Recebido em:

$05 / 09 / 2018$

Aceito em:

$10 / 12 / 2018$

Figura 3 - Comparação da acidez ( ${ }^{\circ}$ Dornic) do leite integral (a), leite desnatado (b) e leite semidesnatado

(c) obtida por diferentes métodos, A e B, para as amostragens realizadas na primavera
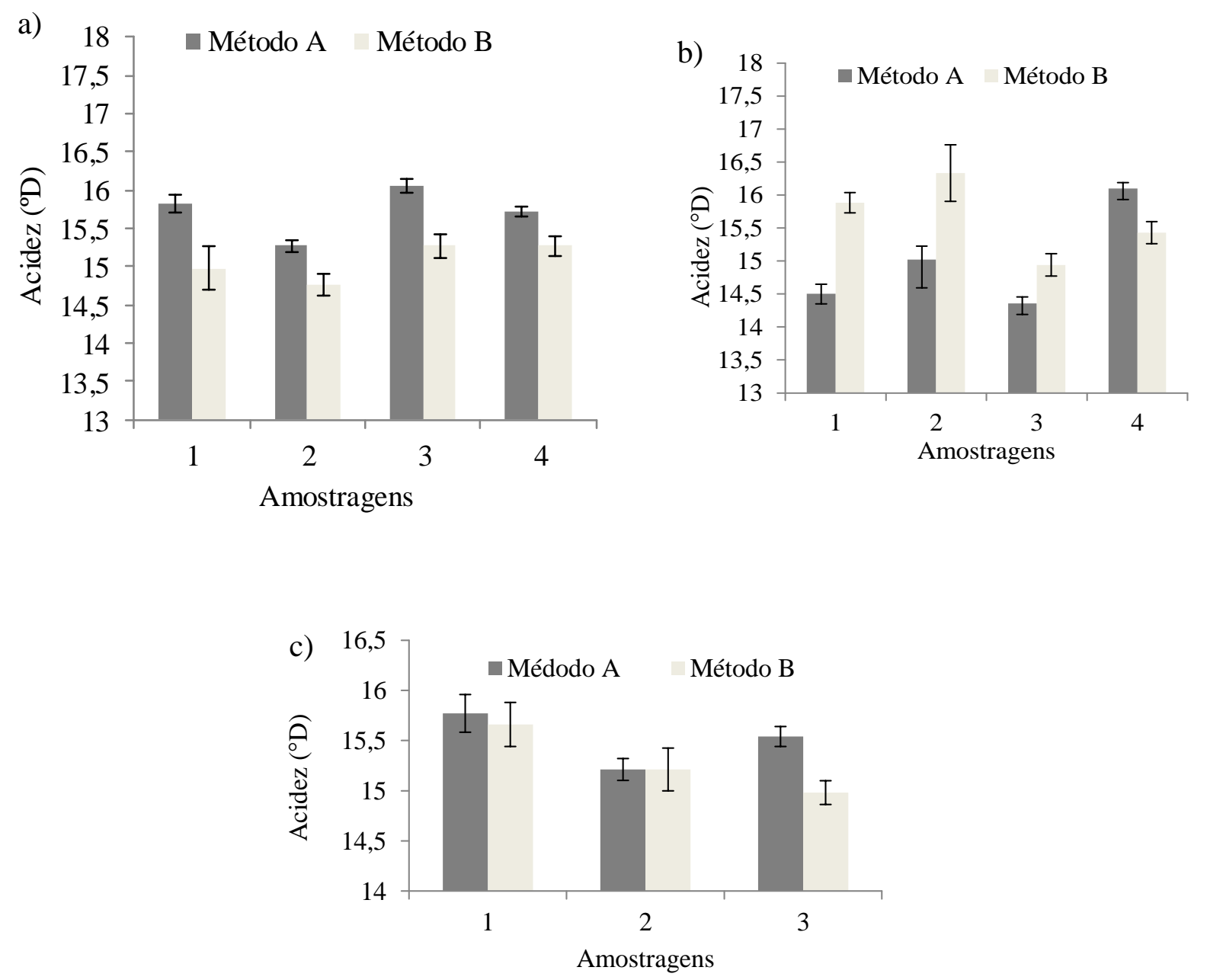

Fonte: elaborado pelo autor (2018) 
Recebido em:

$05 / 09 / 2018$

Aceito em:

$10 / 12 / 2018$

Figura 4 - Comparação da acidez ( ${ }^{\circ}$ Dornic) do leite integral (a), leite desnatado (b) e leite semidesnatado (c) obtidos pelos diferentes métodos A e B para as amostragens realizadas no verão
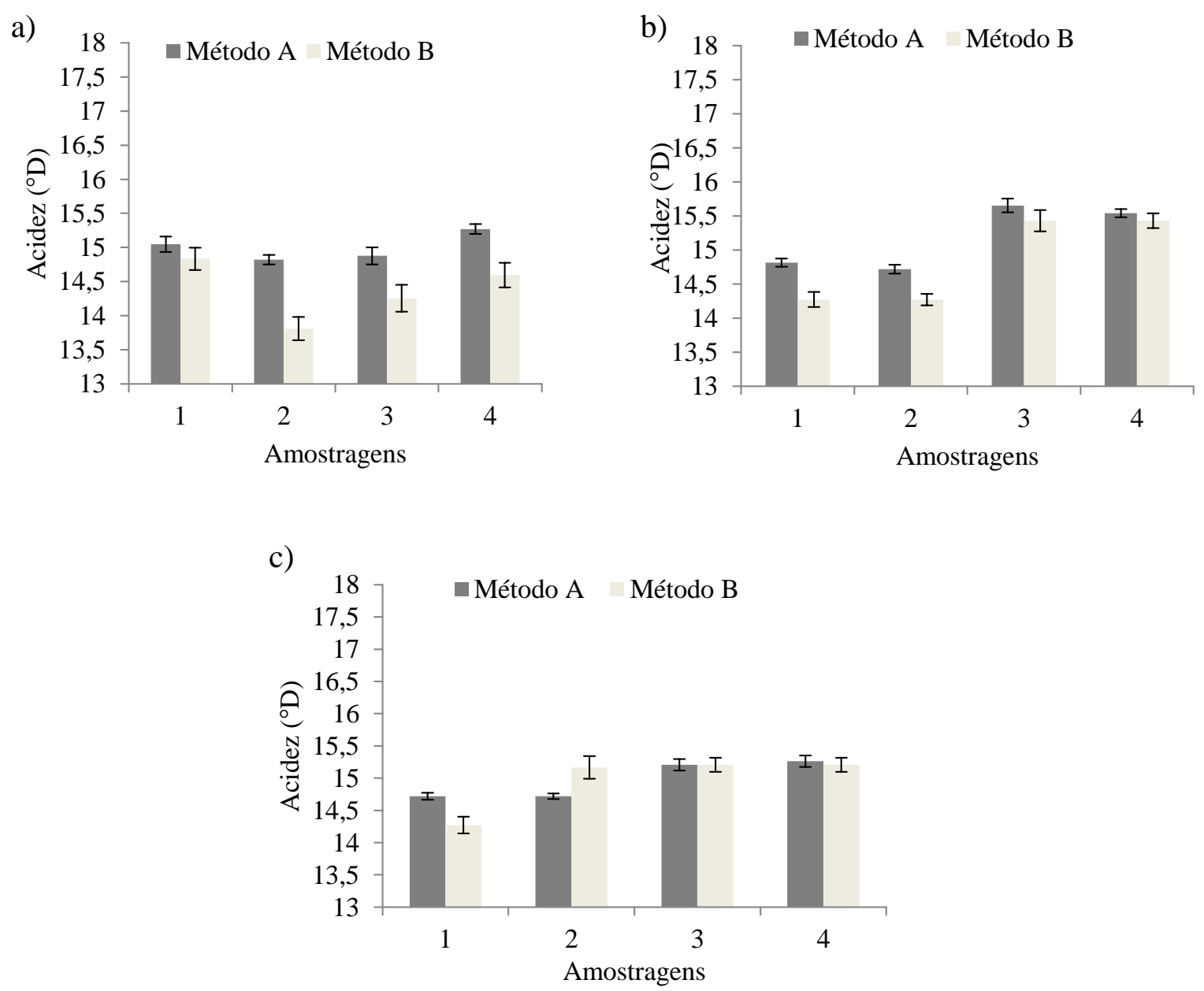

Fonte: elaborado pelos autores (2018)

\section{CONCLUSÃO}

Os resultados da acidez titulável foram analisados em diferentes estações do ano, no mesmo método, para leite integral, semidesnatado e desnatado. Observou-se que para o método A não houve diferença significativa entre as estações. Já para o método B obteve-se variação entre as estações, onde para o leite integral obteve diferença significativa para estação primavera, para o leite desnatado obteve diferença significativa nas estações primavera e verão e para o leite semidesnatado as estações 


\section{Recebido em:}

$05 / 09 / 2018$

Aceito em:

$10 / 12 / 2018$

outono, inverno e primavera diferiram significativamente em relação ao verão.

Analisando-se os resultados entre os métodos na mesma estação do ano, os resultados diferiram significativamente para o leite integral nas estações primavera e verão, para o leite desnatado nas estações inverno e verão e para o leite semidesnatado nas estações primavera e verão.

Os resultados desta pesquisa permitiram verificar que existem diferenças entre os resultados obtidos por ambos os métodos na mesma amostra de leite e em diferentes estações. No entanto, os resultados obtidos usando o método $\mathrm{A}$ e o método $\mathrm{B}$ não são equivalentes, o que corrobora com relatos de laboratórios da indústria de lacticínios. Considerando a revogação da IN 68/2006 pela IN 30/2018, o que passa a valer é o método A com acidez expressa em g de ácido lático/100 mL, descrita no Manual de Métodos Oficiais para Análises de Alimentos de Origem Animal (BRASIL, 2018).

\section{AGRADECIMENTOS}

Primeiramente a Universidade do Estado de Santa Catarina pela oportunidade em participar dessa pesquisa, Aurora Alimentos Unidade Pinhalzinho pela disponibilidade das amostras de leite UHT e FAPESC.

\section{REFERÊNCIAS}

ALAIS, C. Ciencia de la leche. Principios de técnica lechera. In Física y Fisicoquímica de la leche. Compañía Editorial Continental, Barcelona, p. 187-195, 1971.

AOAC. Official Methods of Analysis. 15th ed. Association of Official Analytical Chemists, Arlington, VA, 1990.

BRASIL. Ministério da Agricultura, Pecuária e Abastecimento. Instrução normativa número 30, de 26 de junho de 2018. Estabelece como oficiais os métodos constantes do Manual de Métodos Oficiais para Análise de Alimentos de Origem Animal, indexado ao International Standard Book Number (ISBN). Diário Oficial da União, Brasília, 13 de julho de 2018, seção 1, $\mathrm{n}^{\mathrm{o}} 134$, p. 09.

BRASIL. Ministério da Agricultura, Pecuária e Abastecimento. Instrução Normativa número 62, de 29 dezembro de 2011. Regulamento Técnico de Produção, Identidade e Qualidade do Leite Tipo A Pasteurizado e do Leite cru Resfriado e o Regulamento Técnico da Coleta de Leite Cru Refrigerado e seu Transporte a Granel. Diário Oficial da União, Brasília, 29 de dezembro de 2011.

BRASIL. Ministério da Agricultura, Pecuária e Abastecimento. Instrução Normativa número 68, de 12 de dezembro de 2006. Estabelece métodos analíticos físico-químicos oficiais para leite e produtos lácteos. Diário Oficial da República Federativa do Brasil, Brasília, 2006. 
BRASIL. Ministério da Agricultura Pecuária e Abastecimento. Departamento de Inspeção de Produtos de Origem Animal. Portaria 370, de 4 de setembro de 1997. Regulamento técnico para fixação de identidade e qualidade do leite UHT (UAT) Diário Oficial da União, Brasília, n. 172, 8 set. 1997.

BRITO, J.R.F.; SOUZA, G.N.; FARIA, C.G.; MORAES, L.C.D. Procedimentos para coleta e envio de amostras de leite para determinação da composição e das contagens de células somáticas e de bactérias, Embrapa gado de leite, . Juiz de Fora. p. 1-6, 2007.

CATTANEO, T.M.P.; HOLROYD, S.E. Guest editorial: New applications of near infrared spectroscopy on dairy products. Journal of Near Infrared Spectroscopy, v. 21, p. 307-310, 2013.

COSTA SOBRINHO, P.D.S.; MARÇAL, F.C.A.; PINHEIRO, J.S.; ALMEIDA, H.G.; PIRES, C.V.; SANTOS, A.S. Bacteriological quality of raw milk used for production of a Brazilian farmstead raw milk cheese. Foodborne Path Disease, Kansas City, v. 2, n. 9, p.138-144, fev. 2012.

ELGERSMA, A.; ELLEN, G.; VAN DER HORST, H.; BOER, H.; DEKKER, P.R.; TAMMINGA, S. Quick changes in milk fat composition from cows after transition from fresh grass to a silage diet. Animal Feed Science and Technology. v. 117, n. 12, p.13-27, nov. 2004.

FABRO, M.A.; MILANESIO, H.V.; ROBERT, L.M.; SPERANZA, J.L.; MURPHY, M.; RODRÍGUEZ, G.; CASTAÑEDA, R. Technical note: Determination of acidity in whole raw milk: Comparison of results obtained by two different analytical methods. Journal of Dairy Science, Champaign, v. 89, n. 3, p. 859-861, mar. 2006.

FERNANDES, R.F., PEREIRA, A.S.F., PINHO, L de. Influência da sazonalidade em parâmetros físico-químicos do leite cru recebido por um laticínio no norte de Minas Gerais. Revista do Instituto de Laticínios Cândido Tostes, Juiz de Fora, v. 68, n. 393, p. 36-41, jul/ago. 2013.

FOSCHIERA, J.L. Indústria de laticínios, industrialização do leite, análises, produção de derivados. Editora: Suliani Editografia Ltda, Porto Alegre- RS, 2004.

FREDEEN, A.H. Considerations in the nutritional modification of milk composition. Animal Feed Science and Technology, Amsterdam, v. 59, n. 1, p. 185-197, 1996.

GONZÁLEZ, F. H. D.; DÜRR, J.W.; FONTANELI, R.S. Uso do leite para monitorar a nutrição e o metabolismo de vacas leiteiras. Porto Alegre: Gráfica, 77p, 2001. 
GAUCHERON, F. The minerals of milk. Reproduction Nutrition Development, EDP Sciences, v. 45, n. 4, p. 473- 483, jan. 2005.

GIACOMETTI, F.; SERRAINO, A.; FINAZZI, G.; DAMINELLI, P.; LOSIO, M.N.; ARRIGONI, N.; PIVA, S.; FLORIO, D.; RIU, R.; ZANONI, R.G. Sale of raw milk in northern Italy: food safety implications and comparison of different analytical methodologies for detection of foodborne pathogens. Foodborne Pathogens and Disease, New Rochelle, v. 9, n. 4, p. 293297, abr. 2012.

GODED Y MUR, A. Técnicas modernas aplicadas al análisis de la leche. Inciones Físicas. 1. ed. Madrid: Editorial Dossat, 1966.

GONÇALVES, E. C B A. 2012. Análise de alimentos: uma visão química da nutrição (3a ed.). São Paulo: Varela Editora e Livraria.

HILL B.; SMYTHE B.; LINDSAY D.; SHEPHERD J. Microbiology of raw milk in New Zealand. International Journal of Food Microbiology, v. 157, n. 2, p.305-308, 2012. Instituto Nacional de Racionalización de Materiales - IRAM. Standard n. 14005 and Standard n. 14014. IRAM, Buenos Aires: Argentina, 1976.

KENNEDY, B.W.; SETHAR, M.S.; TONG, A.K.; W.; MOXLEY, J.E. Environmental factors influencing test day somatic cell counts in Holstein. Journal of Dairy Science, Champaign, v.65, n.2, p. 275-280, 1982.

MAGRI, L.P. Quantificação de acidez titulável e pH utilizando técnica potenciométrica como indicador de qualidade do leite bovino.78 f. Dissertação (Mestrado Profissional) - Universidade Federal de Juiz de Fora, Faculdade de Farmácia e Bioquímica. Programa de Pós-Graduação em Ciência e Tecnologia do Leite e Derivados, 2015.

MALACARNE, M.; FIENI, S.; TOSI, F.; FRANCESCHI, P.; FORMAGGIONI, P.; SUMMER, A. Seasonal variations of the rennet-coagulation properties of herd milks in Parmigiano-Reggiano cheese manufacture: comparison between Italian Friesian and Italian Brown cattle breeds. Italian Journal Animal Science, v. 4 (Suppl. 2), p. 242-244, 2005.

MEDEIROS, L.F.D.; VIEIRA, D.H. Bioclimatologia Animal. Rio de Janeiro: Universidade Federal do Rio de Janeiro, 2009.

MOREIRA, A.M.F. Estudo comparativo das técnicas, parâmetros e indicadores de avaliação da qualidade do leite dos Açores - PT e do Estado do Paraná - BR. Dissertação (Mestrado em Tecnologia e Segurança Alimentar), Departamento de Ciências Agrárias, Universidade dos Açores, 
Recebido em:

$05 / 09 / 2018$

Aceito em:

$10 / 12 / 2018$

Angra do Heroísmo, 2014.

MUEHLHOFF, E.; BENNETT, A.; MCMAHON, D. Milk and Dairy Products in Human Nutrition. Food and Agriculture Organization of the United Nations (FAO), Rome, 2013.

OLIVEIRA, C.J.B.; LOPES JUNIOR, W.D.; QUEIROGA, R.C.R.E.; GIVISIEZ, P.E.N.; AZEVEDO, P.S.; PEREIRA, W.E.; GEBREYES, W.A. Risk factors associated with selected indicators of milk quality in semiarid northeastern Brazil. Journal of Dairy Science, Champaign, v. 94, n.8, p. 3166-3175, 2011.

PINTO, C.L.O.; PICCOLO, M.P.; BRITO, M.A.V.P.; MARTINS, M.L.V.; MACÊDO, C.S.; FARIÑA, L.O. Qualidade Microbiológica do leite crú. 1. ed. Viçosa: Empresa de Pesquisa Agropecuária de Minas Gerais, v. 1, p. 235-272, 2013.

REFSHOLT, H.; BRENDEHAUG, J.; BIONG, A. S.; SELMER-OLSEN, E. Milk quality - a futute approach. From the dairy industry's point of view. Journal of Animal and Feed Sciences v. 16 (Suppl. 1), p. 227-239, 2007.

RIEKERINK, R.G.M.O.; BARKEMA, H.W.; STRYHN, H. The effect of season on somatic cell count and the incidence of clinical mastitis. Journal of Dairy Science, Champaign, v. 90, n. 4, p. 1704-1715, apr. 2007.

SANTOS, M.V.; FONSECA, L.F.L. Composição e propriedades físico-químicas do leite. Curso on line - Monitoramento da qualidade do leite. Milkpoint, 16f, p 1-2, 2004.

SMITH, K.L.; TODHUNTERM D.A.; SCHOENBERGER, P.S. Environmental mastitis: cause, prevalence, prevention. Journal of Dairy Science, Champaign, v. 68, n. 6, p. 1531-1553, jun. 2008.

WEGNER, T.N.; SCHUH, J.D.; NELSON, F.E.; STOTT, G.H. Effect of stress on blood leucocyte and milk somatic cell counts in dairy cows. Journal of Dairy Science, Champaign, v.59, n. 5, p. 949-956, may. 1976.

WEST, J. W. Effects of heat-stress on production dairy cattle. Journal of Dairy Science, Champaign, v. 86, n. 6, p. 2131-2144, 2003. 